\title{
Respostas de frangos de corte fêmeas de duas linhagens a dietas com diferentes perfis protéicos ideais
}

\author{
Responses of female broilers from two strain crosses to diets with differing ideal protein profiles
}

\author{
Sergio Luiz Vieira ${ }^{\text {I }}$ Alexandra Reali Olmos ${ }^{\mathrm{II}}$ Josemar Berres ${ }^{\mathrm{II}}$ Dimitri Moreira de Freitas ${ }^{\mathrm{III}}$

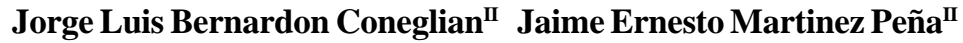

\section{RESUMO}

Foi conduzido um experimento com o objetivo de avaliar a formulação de dietas com diferentes perfis protéicos ideais para frangos de corte fêmeas. Foram usadas aves dos cruzamentos Cobb x Cobb 500 e Ross x Ross 308. As dietas foram fornecidas em um programa alimentar de quatro fases: 1 a 7, 7 a 21, 21 a 31 e 31 a 37 dias de idade. Até os 21 dias de idade, as aves receberam dietas com perfis protéicos ideais altos (A), médios (M) e baixos (B). De 21 dias até o final do experimento, houve uma redistribuição dos tratamentos em que metade das aves recebendo dieta $A$ passaram a receber dieta $B$ e metade daquelas recebendo dieta $B$ passaram $a$ receber dieta $A$. As aves recebendo dieta $M$ permaneceram com o mesmo perfil protéico por todo o período experimental. Foi utilizado um delineamento inteiramente casualizado em arranjo fatorial com três perfis protéicos e duas linhagens até os 21 dias de idade e cinco perfis protéicos ideais e duas linhagens dos 21 aos 37 dias de idade. As aves da linhagem Cobb apresentaram maior peso vivo aos 21 dias de idade $e$ melhor conversão alimentar até o final do experimento, enquanto aves Ross apresentaram maior consumo de ração durante todo o período experimental. Ainda para frangos Ross, a proporção de carne de peito aos 31 dias de idade foi maior e a proporção de coxas + sobrecoxas, aos 31 e 37 dias de idade, menores em relação às aves Cobb. As aves recebendo as dietas $A$ e $M$ até os 21 dias de idade apresentaram respostas zootécnicas similares, ambas superiores às aves recebendo dieta B. A avaliação dos dados aos 31 e 37 dias de idade demonstrou que as aves do programa alimentar $B B$ apresentaram peso vivo semelhante, maior consumo de ração e conversão alimentar pior na comparação com as aves dos demais tratamentos. Já na avaliação após o abate, as únicas diferenças observadas foram relativas à proporção de gordura abdominal aos 31 dias de idade. Foi possível concluir que aves Cobb apresentaram melhor conversão alimentar independentemente do programa alimentar utilizado e que os perfis protéicos ideais médios foram suficientes para maximizar o desempenho tanto sob o ponto de vista de peso corporal quanto de conversão alimentar.

Palavras-chave: aminoácidos, frangos de corte, linhagens, lisina, proteína ideal.

\section{ABSTRACT}

This study was conducted with the objective of evaluating the performance of two broiler strain crosses fed diets having 3 different ideal protein profiles. One day old Cobb x Cobb 500 and Ross x Ross 308 broiler chicks were in a feeding program of 4 phases from 1 to 7,7 to 21, 21 to 31 and 31 to 37 days of age and having high $(H)$, medium $(M)$ and low $(L)$ ideal protein profiles. At 21 days of age, half of the replications fed $H$ and $L$ protein diets changed to $L$ and $H$, respectively, whereas those receiving $M$ remained all the way to the end in the same protein level. The experimental design was completely randomized in a factorial arrangement having 3 ideal protein levels and 2 strain crosses until 21 days of age and 5 ideal protein levels and 2 strains from 21 to 37 days old was used. Cobb broilers had higher body weight at 21 days of age and better feed conversion until the end of the experiment, whereas Ross broilers showed higher feed intake during all the experimental period. At processing, Ross broilers had higher breast meat yield at 31 days old, but Cobb broilers had higher yield of leg quarters both at 31 and 37 days. At 21 days, $H$ and $M$ diets presented similar live performance; however, both were superior when compared to L diets. Differences in body weigh at 31 and 37 days due to feeding programs were not apparent; however birds fed $L$ diets in both periods had poorer feed conversion and higher feed intake than all the other treatments. The only processing difference due to feeding program was an

IDepartamento de Zootecnia, Universidade Federal do Rio Grande do Sul (UFRGS). Av. Bento Gonçalves, 7712, Bairro Agronomia, 91540-000, Porto Alegre, RS, Brasil. E-mail: slvieira@ufrgs.br. Autor para correspondência.

IIPrograma de Pós-graduação em Zootecnia, UFRGS, Porto Alegre, RS, Brasil.

IIIFaculdade de Medicina Veterinária, UFRGS, Porto Alegre, RS, Brasil. 
increased proportion of abdominal fat when birds were fed $L$ diets in one of the two periods. It was possible to conclude that Cobb broilers had better feed conversion independently of the feeding program used and that the $M$ ideal protein levels were adequate to support maximum live performance and carcass yields.

Key words: amino acids, broiler, lysine, ideal protein, strains.

\section{INTRODUÇÃO}

As genéticas predominantes na produção de frangos de corte apresentam características diversas de velocidade de crescimento e rendimento de carne (MOREIRA et al., 2003; CORZO et al., 2005; SANTOS et al., 2005). A produção de frango brasileira atende a mercados muito diversos, o que demanda pesos de carcaça e produtos muito diferenciados. As fêmeas são em geral utilizadas para produzir carcaças ou cortes de baixo peso, pois o seu tamanho adulto é inferior ao dos machos.

Características de rendimento de carcaça e cortes, bem como velocidade de crescimento e eficiência alimentar, também podem ser afetadas pelos planos nutricionais utilizados. O perfil protéico das dietas, neste sentido, é fundamental, pois, além de exercer influência sobre o ganho de peso e a conversão alimentar, também afeta o rendimento de carne (KIDD et al., 1998). O impacto do custo da proteína na dieta é alto e, portanto, aumentos na sua concentração só são justificáveis quando ganhos no desempenho zootécnico ou no rendimento de carne são viabilizados. Recentemente, tem sido demonstrado que ganhos zootécnicos e de rendimento de carne podem ser obtidos com o aumento da densidade protéica das dietas independentemente da genética utilizada (BARTOV \& PLAVNIK, 1998; VIEIRAet al., 2004; KIDD et al., 2005a). Entretanto, existe a possibilidade de que as respostas de cada genética à proteína dietética sejam de magnitudes diferentes, o que indicaria a necessidade de programas protéicos diferenciados para cada uma.

Atualmente, as formulações de rações para frangos de corte são majoritariamente baseadas no conceito de proteína ideal, seguindo a proposta original de MITCHELL (1964). Esta proposta considera relações ótimas entre os aminoácidos essenciais e a lisina e visa a maximizar a eficiência de utilização da proteína da dieta. Existem diversas recomendações de aminoácidos para formulações de dietas para frangos de corte (BAKER \& HAN, 1994ab; NRC, 1994; BAKER, 1997). No Brasil, a maior parte das formulações segue as recomendações de ROSTAGNO et al. (2005), que propõem diferentes possibilidades de planos nutricionais de acordo com o desempenho estimado desejado. Embora existam trabalhos como os de BILGILI et al. (1992) e TOLEDO (2003), recomendações protéicas individualizadas para genéticas distintas devem ser constantemente atualizadas, buscandoseatender ao constante melhoramento a que estas são submetidas.

Reconhecidamente, as exigências de proteína são proporcionalmente superiores em períodos iniciais do desenvolvimento dos animais. Isso pode ser explicado pela menor exigência para gastos de crescimento à medida que as aves se desenvolvem. Desta forma, programas alimentares com maior conteúdo protéico inicial podem acelerar a taxa de ganho de peso e, eventualmente, reduzir o período total necessário para atingir um determinado peso (WIJTTEN et al., 2004).

O presente trabalho foi conduzido com o objetivo de avaliar programas alimentares com concentrações protéicas idealmente balanceadas, seguindo aumentos graduais e disponibilizados a fêmeas das linhagens Cobb X Cobb 500 e Ross X Ross 308.

\section{MATERIAL E MÉTODOS}

O experimento foi conduzido nas instalações do Aviário de Ensino e Pesquisa da Universidade Federal do Rio Grande do Sul, em Porto Alegre, RS, nos meses de agosto e setembro de 2005. De acordo com as normas vigentes nesta instituição, não houve necessidade de submissão do trabalho à comissão de ética. Dois mil e cem frangos de corte fêmeas (1.050 Cobb X Cobb 500 e 1.050 Ross X Ross 308) de um dia de idade foram alojados até os 37 dias de idade em 70 boxes de 1,65 x 1,70 m, (30 aves por boxe), constituindo o segundo lote criado no galpão e também sobre a mesma cama de casca de arroz, ou seja, o ambiente configurou um baixo desafio imunológico. Água e ração foram disponibilizadas ad libitum. As aves foram vacinadas no incubatório contra doença de Marek, bronquite infecciosa e bouba aviária e alojadas sob luz contínua até os 14 dias de idade. A partir dos 15 dias de idade dos frangos, o aviário foi mantido iluminado entre as $6 \mathrm{~h}$ e as $18 \mathrm{~h}$. A temperatura ambiental foi mantida na zona de conforto térmico possível, modulada de acordo com as condições ambientais externas.

As dietas, vegetais, à base de milho, farelo de soja e sorgo, foram formuladas de acordo com resultados de aminogramas previamente realizados, aos quais foram aplicados os coeficientes de digestibilidade de aminoácidos de ROSTAGNO et al. (2005). Os tratamentos consistiram de dois cruzamentos genéticos e de programas alimentares com diferentes perfis 
protéicos ideais. As dietas foram produzidas sem antibióticos promotores de crescimento ou anticoccidianos e foram fornecidas na forma farelada. Foi utilizado um programa alimentar dividido em quatro fases: pré-inicial (1-7 dias), inicial (7-21 dias), crescimento (21-31 dias) e final (31-37 dias).

Os programas alimentares foram aplicados em dois períodos experimentais, conforme pode ser observado na tabela 1 . De 1 a 21 dias de idade, as aves receberam dietas com perfis protéicos ideais altos (A), médios (M) e baixos (B), sendo que de 21 dias até o final do experimento, houve uma redistribuição dos tratamentos em que metade das aves recebendo dieta A passaram a receber dieta $B$ e metade daquelas recebendo dieta $\mathrm{B}$ passaram a receber dieta $\mathrm{A}$. As aves recebendo dieta $\mathrm{M}$ permaneceram recebendo o mesmo perfil protéico por todo o período experimental. Os valores de energia metabolizável e dos nutrientes das dietas de perfil $\mathrm{M}$ foram formulados a partir de informações obtidas junto a integrações do Sul do Brasil. Os perfis A e B foram produzidos a partir de aumentos e reduções de $10 \%$ no valor de lisina digestível relativa a este nível. Para produzir o perfil protéico ideal em todas as dietas, foram mantidas relações de 75 e $65 \%$ entre aminoácidos sulfurados e treonina digestíveis, respectivamente, com a lisina digestível. As formulações tiveram base prática e, portanto, as relações ideais foram mantidas apenas até treonina (Tabela 2).

O estado sanitário do lote foi verificado diariamente, com a eliminação de aves que apresentaram desenvolvimento anormal, sendo estas ocorrências registradas. Semanalmente foram realizadas a pesagem das aves, da ração ofertada e da sobra de ração da semana anterior. A partir desses dados, foram obtidas as variáveis peso vivo, consumo de ração e conversão alimentar. A conversão alimentar foi corrigida de acordo com o peso dos animais mortos. Como o peso inicial das aves foi estatisticamente diferente entre as linhagens (Cobb = 40g e Ross = 39g), o mesmo foi utilizado como covariável no modelo estatístico.

Foram realizados dois abates, um aos 31 e outro aos 37 dias de idade. Em ambos, foram abatidas seis aves por box, selecionadas aleatoriamente e submetidas a jejum prévio de oito horas de forma a permitir o esvaziamento do trato gastrintestinal. Cada ave foi pesada individualmente, atordoada por eletronarcose, sangrada através do seccionamento transversal da veia jugular em cone de sangria por três minutos, escaldada a uma temperatura de $60^{\circ} \mathrm{C}$ por cerca de um minuto, depenada em depenadeira elétrica, eviscerada manualmente e disposta em resfriador estacionário a $2^{\circ} \mathrm{C}$ por 3 horas. As carcaças foram então suspensas por três minutos e pesadas. Em seguida, estas foram submetidas a cortes comerciais realizados por efetivo treinado de integradora local. Coxas + sobrecoxas com osso, peito desossado, asas, dorso e gordura abdominal foram pesados e expressos como relativos ao peso da carcaça eviscerada.

O experimento foi instalado em arranjo fatorial com rtrês programas alimentares com diferentes perfis protéicos e dois cruzamentos genéticos até os 21 dias de idade. O tratamento com perfil protéico $\mathrm{M}$ teve 14 repetições e os demais tiveram 28 repetições. Após 21 dias de idade, a análise foi realizada em um arranjo fatorial com cinco programas alimentares com diferentes perfis protéicos e dois cruzamentos genéticos constituindo dez tratamentos com sete repetições. Os resultados de mortalidade foram submetidos à transformação para arco seno previamente à análise estatística. As variáveis que apresentaram diferença estatística ao Teste $\mathrm{F}$ foram submetidas ao Teste de Tukey $(\mathrm{P} \leq 0,05)$.

\section{RESULTADOS E DISCUSSÃO}

Os resultados de desempenho zootécnico estão apresentados na tabela 3. Os animais da linhagem Cobb apresentaram maior peso vivo aos 21 dias de idade quando comparados aos da linhagem Ross. Contudo, quando esta resposta foi avaliada aos 31 e 37 dias de idade, não houve diferença significativa entre as linhagens. Estes dados suportam a idéia de que as aves da linhagem Ross apresentam um crescimento inicial inferior às aves da linhagem Cobb e que, posteriormente, apresentam um ganho compensatório evidenciado pelo crescimento superior e pela ausência

Tabela 1 - Programa nutricional e períodos experimentais utilizados no experimento.

\begin{tabular}{|c|c|c|c|}
\hline Pré-Inicial (1 a 7 dias) & Inicial (7 a 21 dias) & Crescimento (21 a 31 dias) & Final (31 a 37 dias) \\
\hline \multicolumn{2}{|r|}{ Alto } & \multicolumn{2}{|r|}{ Alto } \\
\hline \multicolumn{2}{|r|}{ Alto } & \multicolumn{2}{|r|}{ Baixo } \\
\hline \multicolumn{2}{|r|}{ Médio } & \multicolumn{2}{|r|}{ Médio } \\
\hline \multicolumn{2}{|r|}{ Baixo } & \multicolumn{2}{|r|}{ Alto } \\
\hline \multicolumn{2}{|r|}{ Baixo } & \multicolumn{2}{|r|}{ Baixo } \\
\hline
\end{tabular}


Tabela 2 - Composição percentual e química das dietas experimentais.

\begin{tabular}{|c|c|c|c|c|c|c|c|c|c|c|c|c|}
\hline \multirow{2}{*}{ Ingredientes, \% } & \multicolumn{3}{|c|}{ Pré-Inicial } & \multicolumn{3}{|c|}{ Inicial } & \multicolumn{3}{|c|}{ Crescimento } & \multicolumn{3}{|c|}{ Final } \\
\hline & Alta & Média & Baixa & Alta & Média & Baixa & Alta & Média & Baixa & Alta & Média & Baixa \\
\hline Milho & 49,23 & 50,74 & 52,49 & 38,36 & 42,71 & 46,50 & 31,94 & 33,30 & 35,24 & 33,46 & 36,87 & 40,77 \\
\hline Farelo de soja & 40,75 & 40,00 & 39,00 & 36,25 & 33,00 & 30,00 & 32,25 & 31,50 & 30,25 & 31,00 & 28,50 & 25,50 \\
\hline Sorgo & - & - & - & 15,00 & 15,00 & 15,00 & 25,00 & 25,00 & 25,00 & 25,00 & 25,00 & 25,00 \\
\hline Óleo de soja & 4,75 & 4,36 & 3,92 & 5,74 & 4,92 & 4,22 & 6,20 & 5,86 & 5,45 & 6,50 & 5,83 & 5,10 \\
\hline Fosfato bicálcico & 1,82 & 1,82 & 1,85 & 1,72 & 1,70 & 1,72 & 1,65 & 1,65 & 1,65 & 1,40 & 1,42 & 1,41 \\
\hline Calcário & 1,50 & 1,50 & 1,50 & 1,50 & 1,50 & 1,54 & 1,50 & 1,50 & 1,50 & 1,25 & 1,25 & 1,30 \\
\hline Bicarbonato de sódio ${ }^{1}$ & 0,50 & 0,42 & 0,33 & 0,27 & 0,18 & 0,12 & 0,24 & 0,19 & 0,11 & 0,25 & 0,22 & 0,14 \\
\hline DL-Metionina & 0,42 & 0,32 & 0,22 & 0,32 & 0,24 & 0,18 & 0,31 & 0,23 & 0,16 & 0,30 & 0,22 & 0,14 \\
\hline L-Lisina & 0,35 & 0,18 & 0,04 & 0,24 & 0,15 & 0,10 & 0,28 & 0,16 & 0,05 & 0,29 & 0,18 & 0,10 \\
\hline L-Treonina & 0,16 & 0,07 & - & 0,09 & 0,04 & - & 0,14 & 0,07 & - & 0,12 & 0,05 & - \\
\hline Sal comum & 0,23 & 0,28 & 0,32 & 0,22 & 0,28 & 0,33 & 0,25 & 0,28 & 0,32 & 0,22 & 0,25 & 0,31 \\
\hline Cloreto de colina & 0,05 & 0,07 & 0,09 & 0,05 & 0,04 & 0,05 & 0,04 & 0,06 & 0,07 & 0,05 & 0,06 & 0,07 \\
\hline Premix $^{2}$ & 0,20 & 0,20 & 0,20 & 0,20 & 0,20 & 0,20 & 0,20 & 0,20 & 0,20 & 0,20 & 0,20 & 0,20 \\
\hline \multicolumn{13}{|l|}{ Energia e nutrientes ${ }^{3}$} \\
\hline Energia metabolizável $^{4}$ & 3,00 & 3,00 & 3,00 & 3,10 & 3,10 & 3,10 & 3,15 & 3,15 & 3,15 & 3,20 & 3,20 & 3,20 \\
\hline Proteína bruta, \% & 23,38 & 22,85 & 22,26 & 21,58 & 20,26 & 19,08 & 20,23 & 19,76 & 19,13 & 19,76 & 18,68 & 17,45 \\
\hline Metionina + Cistina, \% & 1,07 & 0,98 & 0,88 & 0,91 & 0,83 & 0,74 & 0,84 & 0,77 & 0,69 & 0,78 & 0,71 & 0,64 \\
\hline Lisina, \% & 1,43 & 1,30 & 1,17 & 1,21 & 1,10 & 0,99 & 1,12 & 1,02 & 0,92 & 1,05 & 0,95 & 0,86 \\
\hline Treonina, \% & 0,93 & 0,85 & 0,76 & 0,79 & 0,72 & 0,64 & 0,73 & 0,66 & 0,60 & 0,68 & 0,62 & 0,56 \\
\hline Cálcio, \% & 0,97 & 0,96 & 0,97 & 0,94 & 0,94 & 0,95 & 0,92 & 0,92 & 0,92 & 0,78 & 0,78 & 0,80 \\
\hline Fósforo disponível, \% & 0,50 & 0,50 & 0,50 & 0,47 & 0,47 & 0,47 & 0,45 & 0,45 & 0,45 & 0,40 & 0,40 & 0,40 \\
\hline Potássio, \% & 0,97 & 0,96 & 0,97 & 0,90 & 0,91 & 0,89 & 0,84 & 0,82 & 0,83 & 0,81 & 0,78 & 0,79 \\
\hline Cloro, \% & 0,25 & 0,25 & 0,25 & 0,25 & 0,24 & 0,25 & 0,26 & 0,26 & 0,25 & 0,25 & 0,25 & 0,25 \\
\hline Sódio, \% & 0,23 & 0,23 & 0,23 & 0,17 & 0,17 & 0,17 & 0,17 & 0,17 & 0,17 & 0,17 & 0,17 & 0,17 \\
\hline Colina, mg/kg & 1.800 & 1.800 & 1.800 & 1.600 & 1.600 & 1.600 & 1.600 & 1.600 & 1.600 & 1.500 & 1.500 & 1.500 \\
\hline
\end{tabular}

${ }^{1} \mathrm{O}$ bicarbonato de sódio $\left(\mathrm{NaHCO}_{3}\right)$ pode ser utilizado nas rações como fonte de sódio para facilitar a obtenção do correto balanço eletrolítico dietético (Na+K-Cl) possibilitando uma menor inclusão de cloreto de sódio ( $\mathrm{NaCl}$ ) e, consequentemente, de $\mathrm{Cl}$ em excesso.

${ }^{2}$ Composição por kg de ração: Vit. A: 8.000UI; Vit. D3: 2.000UI; Vit. E: 30mg; Vit. K3: 2mg; Vit. B1: 2mg; Vit. B2: 6mg; Vit. B6: 2,5mg; Pantotenato de Cálcio: 15mg; Biotina: 0,08mg; Ác. Fólico: 1mg; Niacina: 35mg; Vit. B12: 12mcg; Iodo: 0,7mg; Selênio: 0,3mg; Cobre: 10mg; Manganês: 80mg; Zinco: 80mg; Ferro: 40mg; Etoxiquim: 100mg.

${ }^{3} \mathrm{AA}$ em base digestível.

${ }^{4}$ Energia metabolizável em Mcal/kg.

de diferenças significativas ainda antes do fim do período experimental. As aves que consumiram dietas de perfis protéicos A e M apresentaram maiores pesos aos 21 dias; entretanto, essas diferenças não se mantiveram nos períodos subseqüentes. De modo semelhante, BAKER \& HAN (1994a) trabalharam com a elevação no nível de lisina e dos demais aminoácidos essenciais, referenciados nas recomendações de tabelas disponíveis, e verificaram pesos superiores para as aves que consumiram dietas com um mesmo nível de lisina digestível, porém com um superior perfil aminoacídico e um peso ainda maior quando também o nível de lisina foi aumentado.

A conversão alimentar das aves Cobb foi melhor durante todo o experimento, quando comparada com a das aves Ross. Da mesma forma que com o peso vivo, as aves que consumiram dietas de perfil protéico ideal $\mathrm{B}$ nos dois períodos experimentais apresentaram pior conversão alimentar em relação às dos demais tratamentos, os quais foram similares entre si. O 
Tabela 3 - Peso vivo (PV, g), consumo de ração (CONS, g), conversão alimentar (CA) em diferentes idades e índice de eficiência produtiva (IEP) aos 37 dias de idade, de frangos de corte fêmeas das linhagens Cobb x Cobb 500 e Ross x Ross 308 alimentados com dietas de diferente perfil protéico ideal.

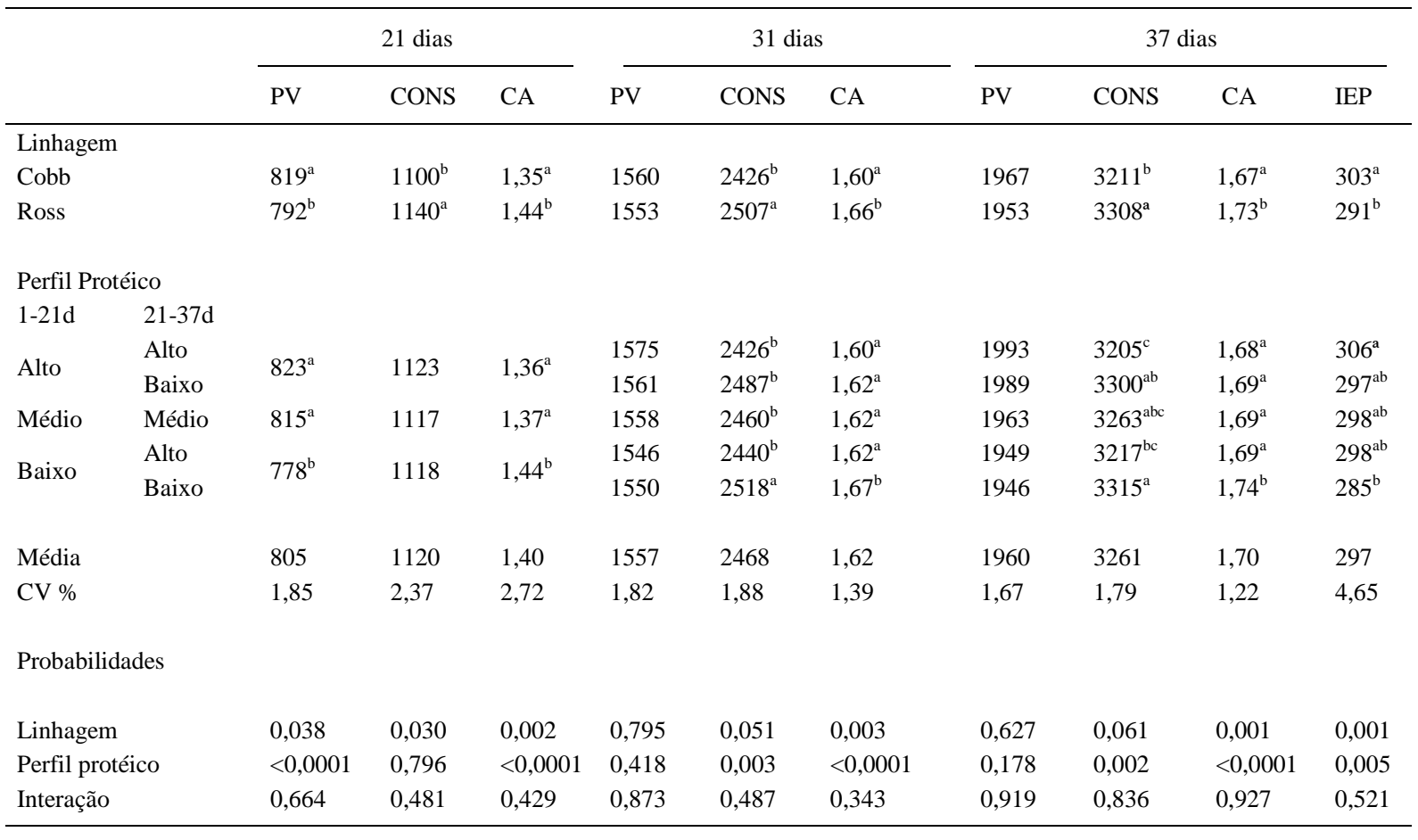

Médias seguidas de letras diferentes na mesma coluna diferem entre si pelo Teste de Tukey a 5\% de significância.

consumo de ração foi superior para as aves da linhagem Ross até os 37 dias de idade. As aves consumindo dietas de perfis protéicos B apresentaram consumo de ração superior em relação às aves que consumiram dietas de $\mathrm{M}$ e A perfis, quando considerado o período de 1 a 31 dias de idade. Já do primeiro aos 37 dias de idade, extremos em consumo foram observados entre as aves com programas alimentares AA e BB, sendo os demais tratamentos similares entre si. VIEIRA et al. (2004), comparando frangos machos das linhagens Cobb e Ross dos 14 aos 35 dias de idade, não observaram diferenças significativas para a resposta conversão alimentar, mas o consumo de ração foi maior para as aves da linhagem Ross. Avaliando respostas de frangos de corte machos à elevação no nível de lisina na dieta, KERR et al. (1999) observaram que dietas com concentrações de lisina superiores às recomendações do NRC (1994) imprimiram uma melhora no ganho de peso e na conversão alimentar dos frangos, embora tenham apresentado restrições quanto à mortalidade.

No presente estudo, não foram encontradas diferenças significativas entre as mortalidades, sendo a média geral durante todo o período experimental de
4,4\%, que pode ser considerada normal. Quando avaliadas as respostas supracitadas em conjunto, através do índice de eficiência produtiva, observa-se, ainda na tabela 3, que as aves da linhagem Cobb sobressaíram-se em relação às da linhagem Ross. As aves que consumiram os níveis protéicos $\mathrm{AA}$ e $\mathrm{BB}$ diferiram entre si para esta resposta, sendo esta diferença favorável às aves que consumiram a dieta $\mathrm{AA}$, enquanto as aves alimentadas com as dietas com os demais perfis protéicos apresentaram índices de eficiência produtiva similares entre si e a esses dois perfis.

Os resultados de rendimento de carcaça, cortes comerciais e gordura abdominal estão apresentados na tabela 4. As aves da linhagem Ross apresentaram maior rendimento de peito aos 31 dias de idade, enquanto que as aves da linhagem Cobb tiveram maior rendimento de coxas + sobrecoxas aos 31 e 37 dias de idade. Nenhuma outra resposta teve efeito da genética. Já com relação aos perfis protéicos, as aves que consumiram dietas com perfil protéico B até 21 dias, passando a A até 37 dias de idade, apresentaram maior proporção de gordura abdominal aos 31 dias de idade em comparação às aves dos demais tratamentos, 
Tabela 4 - Rendimentos de carcaça (RC), peito, coxas + sobrecoxas (C+S), asas e gordura abdominal (GA) de frangos de corte fêmeas das linhagens Cobb x Cobb 500 e Ross x Ross 308, aos 31 e 37 dias de idade, alimentados com dietas de diferente o perfil protéico ideal, \%.

\begin{tabular}{|c|c|c|c|c|c|c|c|c|c|c|c|}
\hline & & \multicolumn{5}{|c|}{31 dias } & \multicolumn{5}{|c|}{37 dias } \\
\hline & & $\mathrm{RC}$ & Peito $^{1}$ & $\mathrm{C}+\mathrm{S}$ & Asas & GA & $\mathrm{RC}$ & Peito $^{1}$ & $\mathrm{C}+\mathrm{S}$ & Asas & GA \\
\hline \multicolumn{12}{|c|}{ Linhagem } \\
\hline \multicolumn{2}{|c|}{ Cobb } & 73,3 & $24,1^{\mathrm{b}}$ & $33,4^{\mathrm{a}}$ & 11,71 & 2,0 & 73,7 & 25,8 & $32,9^{\mathrm{a}}$ & 11,86 & 2,4 \\
\hline \multicolumn{2}{|l|}{ Ross } & 72,6 & $24,7^{\mathrm{a}}$ & $33,0^{\mathrm{b}}$ & 11,70 & 2,2 & 73,1 & 25,8 & $32,4^{\mathrm{b}}$ & 12,21 & 2,6 \\
\hline \multicolumn{12}{|c|}{ Perfil Protéico } \\
\hline $1-21 d$ & $21-37 d$ & & & & & & & & & & \\
\hline \multirow{2}{*}{ Alto } & Alto & 73,0 & 24,7 & 33,3 & 11,78 & $1,9^{\mathrm{b}}$ & 73,7 & 26,3 & 32,4 & 11,94 & 2,4 \\
\hline & Baixo & 73,1 & 24,3 & 33,0 & 11,73 & $2,2^{\mathrm{ab}}$ & 73,5 & 25,6 & 32,7 & 12,05 & 2,4 \\
\hline Médio & Médio & 73,0 & 24,4 & 33,1 & 11,71 & $2,1^{\mathrm{b}}$ & 73,4 & 26,2 & 32,7 & 12,00 & 2,6 \\
\hline \multirow{2}{*}{ Baixo } & Alto & 73,2 & 24,6 & 33,1 & 11,70 & $2,4^{\mathrm{a}}$ & 73,2 & 25,5 & 33,1 & 12,08 & 2,5 \\
\hline & Baixo & 72,4 & 23,9 & 33,5 & 11,61 & $2,0^{\mathrm{b}}$ & 73,3 & 25,4 & 32,5 & 12,10 & 2,4 \\
\hline \multicolumn{2}{|l|}{ Média } & 72,9 & 24,4 & 33,2 & 11,71 & 2,1 & 73,4 & 25,8 & 32,7 & 12,04 & 2,5 \\
\hline \multicolumn{2}{|l|}{$\mathrm{CV} \%$} & 1,50 & 3,19 & 1,50 & 2,96 & 12,68 & 1,03 & 4,17 & 1,99 & 3,49 & 9,37 \\
\hline \multicolumn{12}{|c|}{ Probabilidades } \\
\hline \multicolumn{2}{|c|}{ Linhagem } & 0,311 & 0,005 & 0,001 & 0,979 & 0,241 & 0,264 & 0,948 & 0,007 & 0,250 & 0,216 \\
\hline \multicolumn{2}{|c|}{ Perfil protéico } & 0,329 & 0,121 & 0,192 & 0,794 & 0,001 & 0,467 & 0,091 & 0,099 & 0,858 & 0,183 \\
\hline \multicolumn{2}{|c|}{ Interação } & 0,415 & 0,204 & 0,082 & 0,380 & 0,555 & 0,615 & 0,170 & 0,291 & 0,558 & 0,930 \\
\hline
\end{tabular}

Médias seguidas de letras diferentes na mesma coluna diferem entre si pelo Teste de Tukey, a 5\% de significância.

${ }^{1}$ Pectoralys major + Pectoralys minor sem osso.

enquanto nenhuma outra resposta pôde ser atribuída ao perfil protéico das dietas. As respostas de desempenho zootécnico e rendimento de carcaça e cortes não apresentaram interações entre linhagem e perfil protéico ideal.

No mercado atual da avicultura de corte, a disponibilidade de cruzamentos genéticos é limitada, sendo as duas linhagens utilizadas neste estudo as predominantes. As características genéticas para respostas zootécnicas e rendimentos de carne são modificadas ano após ano; entretanto, há referências de que as exigências de nutrientes ou energia para otimizar ganhos de diferentes genéticas possam ser diferentes (BILGILI et al., 1992). Todavia, no presente estudo, os benefícios obtidos com a modificação do regime protéico da dieta determinaram respostas similares para as duas genéticas estudadas. VIEIRA et al. (2004) e KIDD et al. (2005b) demonstraram que aves alimentadas com dietas contendo uma alta densidade de aminoácidos apresentaram maior rendimento de carne de peito e menor conversão alimentar e percentual de gordura abdominal quando comparadas com aves que consumiram dietas com uma densidade baixa de aminoácidos. SIBBALD \& WOLYNETZ (1986) demonstraram que as exigências de lisina para otimizar o acréscimo de carne de peito em frangos de corte são superiores àquelas para ótimo peso corporal. Já HOLSHEIMER \& RUESINK(1993) e KIDD et al. (1998) demonstraram que a lisina dietética na fase inicial tem impacto sobre a deposição de carne de peito em fases subseqüentes da vida de frangos de corte. Atualmente, a discussão das exigências de lisina tem que considerar as exigências dos demais aminoácidos limitantes. Sob o ponto de vista prático, pelo menos aminoácidos sulfurados e treonina, para os quais é possível modificar a relação através da suplementação com aminoácidos sintéticos, devem ter uma relação ideal estabelecida.

É possível que o fornecimento de aminoácidos em quantidade superior àquela recomendada pelas tabelas nos períodos iniciais da vida de frangos de corte com redução marginal em períodos posteriores permita prover um mecanismo para os nutricionistas que possibilite a redução do custo da ração em relação ao peso corporal do frango (KIDD et al., 2005b). No entanto, no presente trabalho, o uso de perfil protéico ideal $\mathrm{M}$ do início ao fim do experimento permitiu máximo desempenho zootécnico, sem perdas em rendimentos de carcaça e cortes, da mesma forma 
que com programas alimentares passando de $\mathrm{A}$ a $\mathrm{B}$ ou de B a A. Conforme KIDD et al. (2004), frangos de corte machos são mais sensíveis a alterações na concentração aminoacídica da dieta que fêmeas.

\section{CONCLUSÕES}

De modo geral, os frangos de corte fêmeas da linhagem Cobb submetidos a dietas com diferentes perfis protéicos ideais apresentaram respostas produtivas superiores aos frangos da linhagem Ross sob essas mesmas condições. O fornecimento de dietas com $\mathrm{M}$ perfil protéico ideal foi suficiente para maximizar o desempenho zootécnico de frangos de corte fêmeas das duas linhagens estudadas.

\section{AGRADECIMENTOS}

À Fundação de Amparo à Pesquisa do Estado do Rio Grande do Sul (FAPERGS), pelo suporte financeiro parcial; à empresa Doux-Frangosul, pelo fornecimento de matériasprimas; e à empresa Ajinomoto Biolatina Ind. e Com. Ltda, pelo fornecimento de aminoácidos sintéticos e execução de aminogramas.

\section{REFERÊNCIAS}

BAKER, D.H.; HAN, Y. Ideal amino acid profile for chicks during the first three weeks post hatching. Poultry Science, Champaing, v.73, p.1441-1447, 1994a.

BAKER, D.H. Ideal amino acid profiles for swine and poultry and their applications in feed formulation. St. Louis, MO: Biokyowa, 1997. p.1-21.

BAKER, D.H.; HAN, Y. Digestible lysine requirement of male and female broiler chicks during the period three to six weeks post hatching. Poultry Science, Champaing, v.73, p.17391745, 1994b.

BARTOV, I.; PLAVNIK, I. Moderate excess of dietary protein increases breast meat yield of broiler chicks. Poultry Science, Savoy, v.77, p.680-688, 1998.

BILGILI, S.F. et al. Strain-cross response of heavy male broilers to dietary lysine in the finisher feed: live performance and further-processing yields. Poultry Science, Savoy, v.71, n.5, p.850-858, 1992.

CORZO, A. et al. Dietary amino acid density effects on growth and carcass of broilers differing in strain cross and sex. Journal of Applied Poultry Research, Savoy, v.14, n.1, p.1-9, 2005.

HOLSHEIMER, J.P.; RUESINK, E.W. Effect on performance, carcass composition, yield, and financial return of dietary energy and lysine levels in starter and finisher diets fed to broilers. Poultry Science, Savoy, v.72, p.806-815, 1993.
KERR, B.J. et al. Lysine level increases live performance and breast yield in male broilers. Journal of Applied Poultry Research, Savoy, v.8, p.381-390, 1999.

KIDD, M.T. et al. Broiler responsiveness (Ross $\times 708$ ) to diets varying in amino acid density. Poultry Science, Savoy, v.84, p.1389-1396, 2005a.

KIDD, M.T. et al. Amino acid density and l-threonine responses in Ross broilers. International Journal of Poultry Science, Faisalabad, v.4, n.5, p.258-262, 2005b.

KIDD, M.T. et al. Increasing amino acid density improves live performance and carcass yields of commercial broilers. Journal of Applied Poultry Research, Savoy, v.13, p.593-604, 2004.

KIDD, M.T. et al. Lysine levels in starter and grower-finisher diets affect broiler performance and carcass traits. Journal of Applied Poultry Research, Savoy, v.7, p.351-358, 1998.

MITCHELL, H.H. Comparative nutrition of man and domestic animals. New York, NY: Academic, 1964. 840p.

MOREIRA, J. et al. Evaluation of performance, carcass yield and breast meat quality in broilers of conformation versus conventional strain. Revista Brasileira de Zootecnia, Viçosa, v.32, n.6, suppl.1, p.1663-1673, 2003.

NRC - National Research Council. Nutrient requirements of poultry. 9.rev.ed. Washington, DC: Natl. Acad., 1994. $155 p$.

ROSTAGNO, H.S. et al. Tabelas brasileiras para aves e suínos. 2.ed. Viçosa, MG: UFV, 2005. 186p.

SANTOS, A.L. et al. Estudo do crescimento, desempenho, rendimento de carcaça e qualidade de carne de três linhagens de frango de corte. Revista Brasileira de Zootecnia, Viçosa, v.34, n.5, p.1589-1598, 2005.

SIBBALD, I.R.; WOLYNETZ, M.S. Effects of dietary lysine and feed intake on energy utilization and tissue synthesis by broiler chicks. Poultry Science, Savoy, v.65, p.98-105, 1986.

TOLEDO, G.S.P. Aplicação dos conceitos de proteína ideal e proteína bruta sobre o desempenho composição e rendimento de carcaças de frangos de corte. 2003. 214f. Tese (Doutorado em Zootecnia) - Universidade Federal do Rio Grande do Sul.

VIEIRA, S.L. et al. Responses of growing broilers to diets with increased sulfur amino acids to lysine ratios at two dietary protein levels. Poultry Science, Savoy, v.83, p.1307-1313, 2004.

WIJTTEN, P.J.A. et al. Effects of different dietary ideal protein levels on male and female broiler performance during different phases of life: Single phase effects, carryover effects, and interactions between phases. Poultry Science, Champaign, v.83, n.2, p.2005-2015, 2004. 